\title{
Erva mate em debate: Federico Borromeu, jesuítas e médicos
}

"Erva mate" in discussion:

Federico Borromeu, jesuíts and doctors

Marina Massimi ${ }^{*}$

Resumo: O trabalho aborda o processo de circulação e transmissão de saberes acerca da erva mate, iniciado pela correspondência epistolar entre Federico Borromeu, Cardeal da cidade de Milão, o missionário jesuíta Diego de Torres Bollo e outros informantes da Companhia, e o médico milanês Iacopo Antonio Clerici. Focam-se diferentes modalidades de apropriação das informações recebidas da America Latina, em conformidade ao universo cultural e religioso dos receptores.

Palavras-chaves: Erva mate; Federico Borromeu; Diego de Torres Bollo; Iacopo Antonio Clerici; transmissão e apropriação de saberes.

Abstract: The paper deals with the process of circulation and transmission of knowledge about the "erba mate", initiated by correspondence between Federico Borromeu, Cardinal of the city of Milan, the Jesuit missionary Diego de Torres Bollo and other informants of the Company, and the Milanese physician Iacopo Antonio Clerici. Different modes of appropriation of the information received from Latin America are focused, according to the cultural and religious universe of the recipients.

Keywords "Erva mate"; Federico Borromeu; Diego de Torres Bollo; Iacopo Antonio Clerici; Transmission and appropriation of knowledge.

*Faculdade de Filosofia, Ciências e Letras - Universidade de São Paulo. E-mail: mmassimi3@ yahoo.com 
Recibido: 5 de octubre de 2017.

Evaluado: 4 de noviembre de 2017. 


\section{Introdução}

A recente historiografia da ciência foca os processos de apropriação dos conhecimentos transmitidos através de intercâmbios entre os povos, no âmbito das historias culturais locais. Safier (2008; 2010), ao estudar os efeitos das expedições científicas europeias no Novo Mundo, investiga o processo de apropriação de saberes, observações, objetos, pelos europeus evidenciando a ocorrência de alterações na prática das ciências empíricas da Europa a partir do contacto com os Novos Mundos. Ao mesmo tempo, estuda as alterações ocorridas nas culturas locais por onde os cientistas europeus transitaram. Raj (2013) assinala a relevância das mudanças que ocorrem na circulação do conhecimento em virtude das interconexões entre sujeitos, práticas e ideias nos encontros entre as culturas: na medida em que as fronteiras entre culturas se tornam fluidas, há uma verdadeira reconfiguração de formas de conhecimento e de práticas.

Tais estudos empregam uma categoria da historiografia recente, proposta por $\mathrm{R}$. Chartier: o conceito de apropriação. Segundo esse autor, "a apropriação visa uma história social dos usos e das interpretações", voltando a atenção "para as condições e os processos que, muito concretamente, sustentam as operações de produção do sentido (na relação de leitura, mas em tantos outros também." (Chartier, 1991, p. 180). A ênfase é na "pluralidade dos empregos e das compreensões" dos saberes, transmitidos e na "liberdade criadora - mesmo regulada - dos agentes" (idem). Em suma, investigar a circulação de saberes e sua transformação local tendo em vista o contexto particular, implica que as significações das informações aprendidas são definidas a partir deste contexto.

No presente artigo, propomos um exemplo deste processo evidenciado pela leitura de fontes ligadas à figura do cardeal Federico Borromeu (1564-1631), importante prelado milanês: trata-se de algumas missivas retiradas do corpo da correspondência epistolar do Cardeal e de anotações acerca de documentos informativos recebidos, de sua autoria; e de cartas e informes a eles enviados, elaborados por jesuítas missionários nos territórios latino-americanos. Borromeu tinha uma ligação particular com as missões jesuíticas latino-americanas, devido ao encontro e amizade com um dos protagonistas desta empresa: o espanhol Diego de Torres Bollo (1552-1638). O cardeal viveu sua existência entre Roma e Milão cidade da qual se tornara bispo; ao passo de que Torres Bollo, nascido na Espanha, viveu e atuou em várias partes da America Latina, falecendo na Bolívia, em 1638. Os dois tinham-se encontrado na Itália na ocasião de uma visita do espanhol junto ao Padre Geral da Companhia em Roma, entre 1660 e 1604. Desse modo, estabelecera-se troca de correspondência epistolar, e também de informações e objetos que despertavam a curiosidade de Borromeu. Dentre eles, atraem especialmente a atenção do cardeal, as noticias acerca de uma erva chamada "caá", ou "mate". A partir das informações iniciais transmitidas pelas cartas, se desencadeia um processo de apropriação que envolve: a recepção de informações advindas de outras fontes; a remessa de objetos; o estimulo a investigações junto à comunidade cientifica local.

Com efeito, Borromeu não se limita a receber e registrar as informações dos missionários, mas reflete sobre elas buscando significações daquela erva desconhecida em sua bagagem cultural; e também nos conhecimentos científicos de sua época. Por isto, além das informações obtidas pela leitura de cartas e informes dos missionários,

\footnotetext{
${ }^{1}$ Os guaranis chamavam a erva "caá". Ao longo do tempo, acabou por ser definida pela cabaça utilizada para seu uso, segundo o termo quéchua "mati". Os castelhanos transformaram o termo em "mate" e mais tarde chamaram "herba del Paraguay" (Freire, 2011).
}

5 Marina Massimi. Erva mate em debate: Federico Borromeu, jesuítas e médicos ... 3-20. 
também solicita o parecer de um famoso medico milanês. Realiza-se assim um processo de apropriação de conhecimentos advindos de um contexto outro à luz do universo cultural do destinatário da correspondência. Este fenômeno é possibilitado entre outros pela posição cultural de Borromeu; assim como pela relação de amizade e estima que Torres Bollo travou com ele na ocasião da visita em Milão e que cultivou até o fim da vida através do envio de missivas. Delinearemos aqui o processo de construção de conhecimentos acerca da "erva do Paraguai" ou erva mate, assim como elaborado por Borromeu e seus informantes.

\section{$O$ contexto de recepção das informações: o mundo de Federico Borromeu}

De onde brotava a confiança do cardeal Federico nos informantes autores do referido documento? E qual era o contex to cultural de recepção das informações recebidas e no qual Borromeu vivia? Para responder a essas questões será importante reconstruir os elos intercorrentes entre o prelado e a Companhia de Jesus, a partir da biografia e do universo histórico de Borromeu.

Federico, filho da tradicional família lombarda dos condes Borromeu, nasceu em 1564 e viveu grande parte de sua vida na cidade de Milão, na Itália. Sua história se entrelaça com a história do lugar: Milão, feudo imperial regido pela família Sforza, devido à falta de descendência do ultimo duque Francisco II, foi anexo ao Império de Carlos V a partir de 1535 . Perdeu assim a condição de centro livre de poder para se tornar cidade dominada e submetida às Constitutiones dominii mediolanensis promulgadas por Carlos em 1541. Entre 1563 e 1584, Carlo Borromeu (1538-1584), primo de Federico, fora bispo da cidade, assumindo o ônus de atuar nela e na diocese toda, os decretos do Concílio de Trento. Na empreitada, o prelado teve que enfrentar a hostilidade do governo espanhol e de algumas ordens religiosas fincadas em seus privilégios. A vida de Carlo foi exemplar, consumindo-se na pregação, nas visitações a todas as paróquias grandes e pequenas de sua extensa diocese, na cura dos doentes, especialmente dos que contraíram a peste.

Federico, em sua juventude, após os estudos nas Universidades de Bologna e Pavia, residiu em Roma a partir de 1586; em 1587 foi nomeado cardeal e em 1593, ordenado sacerdote. Em Roma, Federico desenvolveu intensa vida intelectual, estudando hebraico, teologia, arqueologia; e também pude cultivar o amor pela arte e pelos livros. Ele teve oportunidade também de aprofundar as relações com uma Ordem religiosa que, desde jovem, estimara: a Companhia de Jesus. Prodi (1991) relata que quando Federico descobrira em juventude sua inclinação pela vocação religiosa, pensou em ser membro da Companhia de Jesus, mas seu primo Carlo o persuadira a abraçar o estado de clérigo secular. Ao longo da temporada em Roma, Federico estreitou laços de amizade com o jesuíta e historiador G.P.Maffei, docente de retórica junto ao Colégio Romano a partir de 1565, e autor da obra Historiarum Indicarum (1589). ${ }^{2}$ Não sabemos se já nesse período em Roma, Borromeu conhecera Torres Bollo, ou se o encontro entre eles remonta a

\footnotetext{
${ }^{2}$ Esta obra encontra-se na Biblioteca Ambrosiana constituída por Borromeu uma vez instalado em Milão, e possivelmente foi seu texto de leitura Acerca do tratado de Maffei, Andretta (2007) coloca que pode ser considerada a obra principal de Maffei e que logrou grande sucesso na época devido ao interesse pelas missões no Novo Mundo e no Oriente, de modo a ter várias reedições. $\mathrm{O}$ autor narra em contemporanea a história de Portugal e sua empresa colonial e a das missões da Compania nos territorios colonizados; e aprofunda aspectos politicos e antropológicos se detendo na descrição das diferenças entre as várias culturas. Narra também as histórias de personagens importantes da Companhia de Jesus, como Francisco Xavier, presentes na Etiopia, no Brasil e nas Indias Orientais.
}

6 Marina Massimi. Erva mate em debate: Federico Borromeu, jesuítas e médicos ... 3-20. 
uma visita que este lhe fez em Milão entre 1602 e 1604, na qualidade de procurador da Província jesuítica do Peru (Ugarte, 1934). Em 1595, Federico foi chamado pelo Papa para assumir o cargo de Bispo de Milão. Seguindo as orientações de seu predecessor e primo Carlo: criou um núcleo de colaboradores; realizou visitas pastorais; revitalizou as estruturas eclesiásticas periféricas; ampliou os seminários; criou novas fundações para a formação cultural e religiosa do clero e uma rede de associações religiosas laicas para a instrução, catequese e assistência. ${ }^{3}$ A atuação pastoral de Federico, porém foi dificultada pelas constantes controvérsias com o governo espanhol da cidade. ${ }^{4}$ Muito intensa foi também a atuação cultural de Federico em Milão. Em 1607 fundou a Biblioteca Ambrosiana, dentre as primeiras do Ocidente. Para constituí-la, Borromeu investiu seu patrimônio na aquisição de livros impressos e manuscritos e para realizar esta tarefa enviou colaborados em diversas bibliotecas de Itália, França, Alemanha, Espanha, Grécia e Oriente. Desse modo, conseguiu trinta mil textos impressos e doze mil manuscritos advindos do Oriente, ou da antiguidade grega e romana. A Biblioteca tornou-se um dos maiores centros mundiais de cultura humanística. Além dessa instituição, Borromeu quis promover a criação de um colégio de pesquisadores especializados em diferentes áreas de conhecimento e que tornassem a biblioteca um laboratório para seus estudos, em estreito contato com os centros culturais e científicos da Europa. Pela fundação dessa instituição, o cardeal pretendia contribuir para a retomada de um horizonte cultural na cidade e na região, num período histórico de profunda crise das instituições universitárias e da própria Igreja católica. No âmbito do "Colégio dos doutores", devia também vigorar o estudo de três idiomas antigos e modernos e foi fundada uma imprensa especializada na estampa de textos orientais, com caracteres latinos, gregos, árabes, hebraicos e armênios. Realizaram-se ali os primeiros passos dos estudos linguísticos e gramáticas das línguas árabe e armênia ${ }^{5}$. Em 1618, através da doação de seu patrimônio pessoal, Borromeu criou Pinacoteca Ambrosiana; e, em 1620, a Academia Ambrosiana de pintura ${ }^{6}$.

Como já dito, essa intensa atividade cultural do Cardeal acontecia ao mesmo tempo em que ele encontrava-se profundamente mergulhado em problemáticas de natureza militar, política e religiosa, por seu cargo de cardeal da cidade de Milão: a Guerra dos Trinta Anos (1616-1648); o extermínio dos adeptos aos movimentos de reforma religiosa na vale Valtellina (1620); a eleição do novo Pontífice Gregório XV; a ascensão ao trono espanhol de Felipe III, cuja política mais agressiva ecoou também na cidade de Milão. Desde a ono de 1616 fora nomeado, como Governador de Milão, o espanhol Gomez Suarez de Figueroa. E com este governo, Borromeu protagonizou várias controvérsias quanto à jurisdição eclesiástica, ao ponto que lhe foi necessário defender sua causa em Roma.

De modo geral, diferentemente de seu habilidoso tio Carlo, Federico não foi capaz de compreender as exigências do Estado moderno e de alcançar um acordo factual com o governo civil; e travou, portanto, uma batalha jurídica e diplomática desgastante

\footnotetext{
${ }^{3}$ Fonte importante acerca de sua atividade pastoral é o conjunto de sermões Sacri Ragionamenti (163246), coletânea de sermões pregados, transcritos e por ele mesmo organizados, tendo em vista a edição.

${ }^{4} \mathrm{O}$ escritor italiano Alessandro Manzoni, em seu romance Os esposos prometidos retratou a personalidade do cardeal, um dos protagonistas do enredo, e descreveu os problemas que ele teve que enfrentar ao longo de sua missão.

5 Todas essas atividades constavam nas normas Constitutiones Collegii ac Bibliothecae Ambrosianae, redigidas por Federico.

${ }^{6}$ Entre os mestres pintores, havia artistas de renome como o pintor Cerano, o escultor Giovan Andrea Biffi, os arquitetos Carlo Buzzi e Fabio Mangone.
}

7 Marina Massimi. Erva mate em debate: Federico Borromeu, jesuítas e médicos ... 3-20. 
e ineficaz. Borromeu concebia a figura do bispo como a de um "cristão filósofo", como ele mesmo dissera num discurso ao episcopado (Prodi, 1971), alicerçada num horizonte cultural moldado pelo platonismo e pelo neo-estoicismo e que preconizava o recuo da pessoa ao mundo da interioridade.

A produção intelectual de Federico composta por várias obras impressas, diz respeito às problemáticas fundamentalmente espirituais. ${ }^{7}$ Em seus textos, Borromeu apresenta uma visão contrária ao racionalismo aristotélico. Sua cosmogonia é animada por forças sobrenaturais: o universo é habitado por anjos e demônios, apesar deste mundo sobrenatural ser retratado de modo muito semelhante ao mundo terreno (Prodi, 1971). Dessa visão do mundo, derivaram também suas posições acerca da bruxaria: durante seu episcopado, entre 1599 e 1631, ocorreram várias execuções de suspeitos. Da mesma visão, deriva também a exigência, afirmada em seus escritos, de discernir entre fenômenos sobrenaturais e fenômenos puramente naturais. E, possivelmente, a esta exigência deve-se as investigações que como veremos ele solicitara a um médico milanês de renome, acerca das propriedades da erva mate.

O cardeal era um leitor voraz e curioso, sobretudo no que diz respeito aos aspectos antropológicos; e, frequentemente, redigia cadernos de anotações derivadas pelas leituras e utilizados depois na redação de seus sermões, como exempla. Dentre os pequenos textos de Federico, lembramos alguns: a importância da viagem para a compreensão antropológica encontra-se no escrito Per $i$ viaggi spirituali o sieno osservazioni fatte nei viaggi e nel leggere viaggiatori ${ }^{8}$; o texto Geografia universale (1582-1599) ${ }^{9}$, trata inclusive do Novo Mundo e de seus habitantes, possivelmente inspirado pela leitura das Relações Universais de seu secretário Giovanni Botero, aliás resumo da primeira parte daquele (Albonico, 1990). O retrato traçado por Botero e por Borromeu acerca dos nativos dos territórios latino americanos é na maioria das vezes marcado por traços negativos: por exemplo, os moradores das regiões setentrionais, como Guatemala, Nicaragua, Venezuela, são rotulados como "tendo hábitos barbarissimos, sem leis nem comércio" (fol. 69, trad. nossa); os brasileiros como "bárbaros, sem reis, sem leis, sem religião; fraudulentos, malignos, deditos ao ócio, orgias, bruxarias, magias, e comedores de carne humana" (1582-99/fol. 74). Ainda maior atenção à realidade latino americana è dedicada no livro Paralela Cosmographica de Sede et Apparitionibus Daemonum Liber Unus. ${ }^{10}$, curioso mapa geográfico dos lugares de aparição frequente de seres demoníacos. O retrato da personalidade multifacetada do Cardeal e os textos por ele elaborados fornecem o contexto para compreender sua recepção e interpretação das noticias acerca da erva mate advindas dos territórios latinos americanos.

\footnotetext{
${ }^{7}$ São elas: De ecstaticis mulieribus et illusis (1616). De acquirendo contemplationis habitu; De assidua oratione; De materia assiduae orationis; De naturali ecstasi; De vario revelationum et illusionum genere (1617); De vita Catharinae Senensis monacae conversae (1618); Tractatus habiti ad sacras virgines (due volumi, 1620 e 1623); De actione contemplationis; De vera et occulta sanctitate (1621); Philagios sive de amore virtutis (1623); De cognitionibus quas habent daemones; De Providentia Dei et Illius permissione cum malignis spiritibus; Parallela cosmographica de sede et apparitione daemonum; Canticorum explanatio iuxta literalem sensum (1624); I tre libri de' piaceri della mente cristiana (1625); "L'idiota,ovvero la felicità dell'orare" (1626); De laudibus divinis; De linguis, nominibus et numero angelorum (1628); De insanis quibusdam tentationibus (1629); De vita contemplativa sive de valetudine ascetica (1630); De christianae mentis iucunditate (1632).

${ }^{8}$ Borromeu, F. (sd). Per $i$ Viaggi Spirituali o sieno osservazioni fatte nei viaggi e nel leggere viaggiatori. Biblioteca Ambrosiana [Bami]. G 309 Inf (8).

${ }^{9}$ Borromeu, F. (1582-99). Geografia Universale. Bami: G. 24 Inf (6).

${ }^{10}$ Borromeu, F. (2006). Paralela Cosmographica de Sede et Apparitionibus Daemonum Liber Unus Edizione moderna a cura di Francesca di Ciaca, Roma, Bulzoni, 2006) Bami G 5 Inf F 2202.
}

8 Marina Massimi. Erva mate em debate: Federico Borromeu, jesuítas e médicos ... 3-20. 


\section{A transmissão das informações: a correspondência epistolar entre Federico Bor- romeu e Diego de Torres Bollo e os informes dos jesuítas}

As informações acerca da erva mate chegam ao cardeal através da correspondência entretida com o já citado Diego de Torres Bollo, importante ator da empresa missionária jesuítica na America Latina do fim do século XVI e inícios do século XVII. Portanto, será importante entender o teor destas informações no contexto da biografia e do universo histórico de pertença de Torres Bollo.

Os dados biográficos de Torres Bollo encontram-se no catálogo unificado Lamalle junto ao Arquivo Histórico da Companhia de Jesus em Roma ${ }^{11}$. Essa fonte nos informa que ele nasceu em 1551 em Villalpando (Velha Castelha) e que em 1571 entrou na Companhia de Jesus. Desde 1575, estudara nos Colégios de Avila, Monterrey e Valladolid. Em 1584 foi destinado à missão do Perú junto a um grupo de jesuitas liderado por Padre Baltasar Piñas. Entre 1582 e 1585, ocupou o cargo de superior da residencia jesuitica de Juli. O catálogo del 1583 descreve o jovem Torres Bollo tendo boas capacidades fisicas e desempenhando atividades de confessor e pregador junto a espanhois e indios. A profissão solene dos votos na Companhia ocorreu em Lima aos 15 de junho de 1588. Depois, assumiu a função de retor de vários colégios da Companhia: em 1591, em Cuzco; em 1595, em Quito; em 1599, em Potosi. Em 1600 foi eleito pela Congregação Provincial do Peru, procurador da Província em Roma; e como já foi dito na ocasião desta viagem conheceu Federico Borromeu com quem estreitara profunda amizade. Entre 1601 e 1604, em Roma, conseguiu a aprovação do projeto da divisão da Província do Peru em tres Províncias: Peru; Novo Reino; e Quito. Ele seria provincial do Novo Reino. Regressado em Lima em 1607, dedicou-se à constituição da nova Provincia de Paraguay e Tucuman, e dela se tornou Provincial até 1615. Em 1610, redigiu as primeiras normas das reduções indigenas. Entre 1615 e 1623 ocupou o cargo de Reitor do Colégio de Cordoba. Já idoso, em 1631, encontrava-se junto ao Colégio de La Plata: mesmo envelhecido fisicamente, continuara a pregação junto aos índios, espanhois e escravos africanos. Morreu em 8 de agosto de 1638 a Cuquisaca (La Plata).

Ao longo de sua extensa e intensa vida missionária em América Latina, Torres Bollo enviara constantemente missivas a Federico Borromeu. Esta correspondência epistolar, ao todo quatorze cartas escritas entre 1603 e 1625, encontra-se manuscrita junto a Biblioteca Ambrosiana de Milão. Apenas parte delas foi publicada pelo jesuíta Ruben Vargas Ugarte (1934, pp. 59-82). A redação das cartas de Torres geralmente segue o estilo da retórica jesuítica no que diz respeito à escrita epistolar: ${ }^{12}$ as missivas são estruturadas em cinco partes distintas (salutatio, captatio benevolenciae, narratio, petitio, conclusio). A salutatio expressa cortesia e amizade para com o destinatário; a captatio benevolentiae dispõe as palavras de modo a influenciar as intenções do destinatário; a narratio fornece informações; a petitio é destinada aos pedidos; e, finalmente, a conclusio é uma especie de síntese dos temas tratados destinada a fixar-se na memória do destinatario. As missivas de Torres Bollo ao cardeal seguem com

\footnotetext{
${ }^{11}$ Lamalle 1942, ARSI; SCH 07 (Schedario unificato Lamalle sub nomine); Catálogo Perú 4, I, f. 57; f. 54. f.10; f.22; f. 43; f. 111, n. 291; f. 342, n. 293. Catálogo Paraq. 07, f.3, n.1. Hisp. 2, ff. 164-165; His. Soc. 46, f.2; Necrologio Peru, 15, ff. 151v-152v; Paraq. 15, ff. 46v-47v. Vide também Monumenta Peruana vol. III, p. 199 e 632. Vide também Lozano, 1755; Del Techo, 2005; Storni, 1975; Deckmann Fleck, 2004; Quevedo dos Santos, 2012.

${ }^{12}$ Pécora (2001) evidencia o estilo da composição da correspondência jesuítica regrada pelas normas da retórica clássica e das Constituiçoes da Companhia.
}

9 Marina Massimi. Erva mate em debate: Federico Borromeu, jesuítas e médicos ... 3-20. 
frequencia pontual e são enviadas de diversos lugares. ${ }^{13}$ Os locais de envio e as datas de expedição das cartas documentam a intensa atividade missionária de Torres Bollo e seus continuos deslocamentos ao longo do extenso território latino americano. Nelas, o jesuita tece narrativas detalhadas acerca da atividade missionária e dos problemas encontrados; além de confissões de natureza autobiográfica e de atestados de amizade para com o destinatário. Mas também envia-lhe informações acerca de aspectos peculiares do mundo latino americano destinadas a alimentar a viva curiosidade de Federico.

A correspondência entre Torres e Borromeu inclui também o intercambio de objetos: Borromeu lhe envia terços, relíquias e outras pequenas peças de significação religiosa; ao passo de que Torres lhe remete, através de religiosos que se deslocam da América Latina para Itália, as 'curiosidades' da terra: "Envio a V. S. Ilustríssima algumas pequenas coisas, apesar de a terra ser pobre de tudo"14. Numa carta de 1621, Torres acusa o recebimento de um parecer acerca da "erva" enviado pelo cardeal Federico, "erva" descrita na carta como um dos males da terra:

"Recibí tanbien el parecer de la yerba, y aunque el es que por si solo bastaba a retraer de tan gran males los españoles de estas tierras, pero ellas están tan corruptas y ellos tan arraigados en estos y otros peores vicios, que si no es la mano del Altísimo, y lagrimas de la tierra no pienso ha de bastar otra cosa a remediar tantos males, sino es que su Santidad (por lo menos con los eclesiásticos) pusiese la mano en esto, pues es cierto que mientras ellos fueren delante con este mal ejemplo, no dejaran de seguirlos los que aunque sin guías corren al mal. Y es cierto cosa de admiración, no menos que de compasión, que por un gusto tan sin gusto, y por el tabaco qui es otra cosa casi peor, dejen los eclesiásticos de decir misa, et auferatur (si Deo placet) iuge sacrificium. El mismo lo remedia, que los de acá como dice, predicamos en desierto. También he agradecido y agradezco a V.S. Ill.ma lo que se hizo en el negocio de las monjas que ha sido cosa oportuníssima para mil inquietudes que tenían. Quiera Nuestro Señor que en llegando los recados se ponga todo bien." 15

De onde nascera este juízo? E qual o conteúdo e o autor do parecer em questão?

O juízo negativo acerca da erva dado por Torres é explicado em pormenores por um texto informativo escrito em língua italiana e preservado na Biblioteca Ambrosiana, redigido no século XVII por jesuítas missionários na América Latina: Outro documento dell'erba usata dagli Indiani del Paraguay e Tucuman ${ }^{16}$.

Inicialmente, o texto classifica o emprego da erva entre os índios do Paraguai, como prática demoníaca. E descreve as modalidades comunitárias de tomar a erva: as pessoas encontram-se nas casas e tomam o infuso da erva moída e pisada, uma ou duas vezes por dia, ao longo da semana, em grande quantidade. O consumo da erva estimula

\footnotetext{
${ }^{13}$ De Lima (8 de dezembro de 1604), de Quito (18 de abril de 1605); do Novo Reino de Granata (23 de julho de 1606); de Lima (20 de maio de 1607 e 23 de maio de 1607); de Cordova (1 de fevereiro de 1608); de Santiago do Chile (25 março de 1608, 2 de abril de 1608 e 10 de outubro de 1612); de Cordova de Tucuman (17 de março de 1617, 19 março de 1621, 11 de julho de 1623, e 1 de fevereiro de 1625).

${ }^{14}$ Carta de Diego de Torres a Federico Borromeu de 23 de julho de 1606, enviada do Novo Reino Em: Bami [Biblioteca Ambrosiana] G. 251, 237 e 238 (trad.), pp. 475-476.

${ }^{15}$ Carta de Diego Torres a Federico Borromeu, Cordoba 19 de março de 1621. Bami: G 254 INF 158 FLS 289-290.

${ }^{16}$ Outro documento dell'erba usata dagli Indiani del Paraguay e Tucuman .Bami. R 106 Sup ff 333r334r e f. 335, reproduzidos em Belloni, 1959: 31-40.
} 
movimentos inatuais do estomago de modo a produzir violento vomito. Os autores relatam que, juntamente ao consumo da erva, os usuários comem e bebem vinho de modo desmedido. Em algumas ocasiões, os índios costumam mastigar a erva, que tem sabor muito amargo. Na medida em que o individuo toma o hábito de beber o infuso, ou mastigar o mate, nunca mais o abandona, até morrer. Nesse ponto, o texto retoma a tópica da ação demoníaca nos Novos Mundos, narrando que o diabo em pessoa, tomando formas de porco, se mostra aos índios dentro dos vasos em que bebem o mate ${ }^{17}$. Por sua vez, os espanhóis também bebem o infuso de erva acreditando ser remédio para qualquer doença.

Quais seriam os danos produzidos pela erva e que comprovariam sua malignidade e origem diabólica? Os autores do documento elaboram um longo elenco de razões.

Em primeiro lugar, destacam os perigos encontrados na colheita da erva, que cresce em lugares distantes dos povoados, onde não se acha nenhum tipo de alimento. Freqüentemente ocorre mortandade entre os que a colhem (os autores estimam entre setenta ou oitenta mortos por ano). As causas da mortandade são várias: fome, frio, fogo (para a colheita os índios costumam cercar a erva com fogos), o peso excessivo dos feixes de erva carregados nas costas por não dispor do auxilio de cavalos para transporte. Em segundo lugar, índios e espanhóis que têm este vício e lhe dedicam a maior parte de seu tempo, tornam-se desviados e frágeis no corpo e na alma. Em terceiro lugar, os autores indicam como indício diabólico o fato de que nas reuniões para tomar o mate, a conversa verte acerca de temas superficiais e pecaminosos. Em quarto lugar, os que tomam diariamente o mate, deixam de receber os sacramentos, de participar na missa cantada e de escutar os sermões; e até os sacerdotes que têm este vício, deixam de celebrar a missa e de confessar, mesmo em dias de festa. Os autores comentar ser algo inacreditável a solicitude e ansiedade que os usuários do mate têm em convidar os outros para participar desse habito vicioso, que assim se espalha como peste, ou lepra. Além disto, afirma que o habito causa catarros e fragilidade de estomago, de modo que muitos falecem repentinamente. Em alguns lugares, essa erva é tão cara até alcançar o preço de quatro a oito réis por libra, de modo que os usuários empobrecem até ao ponto de seus filhos andarem nus; e eles também. Por fim, julga-se haver pacto implícito com o Demônio: é indicio disto o fato de que muitos, fascinados, não conseguem se emendar, sejam eles índios, sejam eles espanhóis, nem mesmo pelos sermões e pelas leis reais.

A recepção da carta de Torres e do informe levam Borromeu a investigar quanto à natureza da erva em questão. Para tanto, ele solicita um parecer junto a um médico por ele estimado.

\section{A significação da erva mate na perspectiva da ciência médica do universo borro- maico}

A personagem em questão é o médico milanês Iacopo Antonio Clerici. Após o estudo do caso, ele redigiu um parecer médico a respeito: De Iudicium de symptomatibus consequentibus ad assumptionem herbae cuiusdam qua Indi tuccumani et para-

${ }^{17}$ Acerca da ação demoníaca nos novos mundos: cfr Mello e Souza, 1989. 
guainenses utuntur. O parecer aborda a questão do mate dentro do universo cultural e dos saberes médicos da Milão de sua época.

O laudo analisa os efeitos do mate no sistema gástrico (vomito violento e fome insaciável), reconduzidos à ação do demônio e associados a casos semelhantes ocorridos em Milão, especialmente ao que causara a condenação de Catarina de Medici na fogueira. Esta fora acusada pela morte de seu patrão pelo medico milanês Ludovico Settala (1552-1633) e pelo próprio Clerici, em $1617^{18}$. Clerici inicia individuando as causas pelas quais os remédios induzem efeitos nos corpos: in primeiro lugar, os remédios que possuem qualidades contrárias aos temperamentos; em segundo lugar, a substâncias infusas na matéria prima; em terceiro lugar, causas ocultas de difícil identificação. Afirma que os médicos costumam classificar todas as drogas simples, pelas quais podem ser alterados os corpos humanos, conforme três ordens e diferenças: as qualidades dos elementos (as componentes que prevalecem na mescla e seus os efeitos, que dão nome ao remédio); os poderes das drogas a partir de sua matéria prima; os casos em que a substancia e forma primeira das drogas permanece oculta ao conhecimento sensorial permanecendo desconhecida à arte médica. Nesta categoria, Clerici coloca as substâncias que têm dois tipos diferentes de ação: as que produzem evacuação (por exemplo, vomito, ou secreção); e as que produzem alterações no organismo (por exemplo, os venenos). Clerici indica também a existência de um quarto tipo de drogas que podem produzir efeitos favoráveis (quando possuírem propriedades análogas as do organismo); ou nocivos (quando tenham propriedades contrárias às do organismo).

Além de comparar as características encontradas na erva mate, com esse quadro de referencia elaborado pela medicina, Clerici se propõe a descrever todos os sintomas decorrentes do uso e observados nos índios pelos informantes. O médico afirma que, se não se encontrar nenhuma explicação no quadro de referencia acima citado, será necessário entender os sintomas como efeitos de causas de natureza superior a serem investigadas. Relata que a erva, de gosto amargo, é compressa ao calor, é secada, reduzida em pó fino e tomada com água quente. Age como forte diurético e provoca vomito; o uso frequente causa violentos espasmos no estomago e nos intestinos. Apesar de o vomito em muitos casos lograr benefícios ao organismo por eliminar impurezas nocivas, muitos observadores julgam que o vomito produzido pelo uso da erva mate não seja segundo a natureza e sim não natural, (semelhante a uma hemorragia), por ele ser violento e imoderado. Outro elemento assinalado por Clerici é o fato de que, os índios que usam chás de erva mate manifestam comportamentos de excesso alimentar; e observa que a falta de moderação quanto à comida pode produzir imbecilidade.

Por tudo isto, o médico deduz que os efeitos da erva são de natureza sobre natural. As evidencias são: em primeiro lugar, o fato de que os usuários do chá de erva mate, apesar dos vômitos desagradáveis, persistem naquele habito; em segundo lugar, os efeitos da erva levam as pessoas a afastar-se das praticas religiosas. Por isto, Clerici emite o seguinte laudo:

Tantam hominum ratione utentium stoliditatem, tantam morum ab humanis dissimilitudinem, ita ut in brutas mutati videantur temporis momento, in herbae illius naturalem facultatem referendam esse, abusturdum omnino videtur et ab omni ratione alienum. Cum igitur insufficiens sit vis naturae qualibet ex narratis facultatibus medicamentis adscripsit, ad tot mirandos effectus ad animum praecipue

\footnotetext{
${ }^{18} \mathrm{O}$ caso da infeliz mulher foi lembrado por Manzoni, no capitulo trigésimo primeiro de Promessi sposi.
} 
pertientes producendos, et astrorum ipsorum etiam, quibus a nonnullis impiis tantum tribui solet, reliquum est ut in potestatem aliquam superiorem reducantur: non in angelorum bonorum, aut Dei; execrabilis enim esset in eum blasphemia. Restat ergo ut in Demonem referantur ob pactum implicitum cume o initum, quod statuitur credendum in articulis Sorbonae Paris art. 3 hisce verbis: "et indendimus esse pactum implicitum in omni observatione superstitiosa, cuius effectus non debet a Deo vel natura rationabiliter expectari (sd, p. 36).

Para o médico milanês, a erva mate evidencia a ação de Satanás no meio dos nativos latino americanos, sendo esta hipótese consolidada também pelas observações de diversos historiadores. Quando os efeitos são contrários à ordem da natureza, eles são semelhantes aos que se observa no malefício amoroso: o demônio altera o equilíbrio das partes do corpo, afeta os órgãos da potencia apetitiva, produz desordem nos espíritos animais, ou seja, nos nervos, estimula o funcionamento exagerado da imaginação, torna os humores mais densos, produz imbecilidade, condutas impuras, confusão mental e incapacidade de uso da razão, movimentos descontrolados do corpo, e afetos e desejos desordenados; as potencias sensitivas são mobilizadas por fortes paixões. A evidência de que os efeitos da erva sejam diabólicos, é comprovada por Clerici ao evocar o já citado caso clinico por ele acompanhado junto ao colega Ludovico Settala, referente a milanês Catarina Medici acusada de ter envenenado seu patrão senador Luigi Melzi d'Eril sendo torturada e executada na fogueira pela acusação de bruxaria, no ano de $1617^{19}$. Clerici observa que os sintomas vivenciados por Melzi d'Eril atingiram a área gástrica (fortes dores de estomago), do mesmo modo como acontece aos usuários do mate. Em suma, os efeitos da erva mate são aproximados aos dos venenos usados pelas bruxas.

A compreensão do sentido deste parecer se faz possível somente se considerarmos o contexto da ciência médica na Milão borromaica. Segundo Belloni, a medicina milanesa começou a mostrar uma dimensão organizada a partir da segunda metade do século XIV, época da fundação do Estudo Geral de Pávia por Gian Galeazzo Sforza. Dois aspectos caracterizam a situação sanitária da cidade: a presença na cidade dos hospitais nascidos como fundações de caridade cristã; e a ocorrência da peste que avassalou aquela região ao longo de três séculos, desde o século XIV até ao século XVII: os surtos na época de Carlos V (1524); na de Carlos Borromeu (1576-7); e na de Federico Borromeu (1629-1632). Esse fato acarretou a necessidade de promulgar normas médicas e higiênicas para conter a epidemia, como a criação dos lazaretos, a partir de 1488; a instituição do Magistrado da Saúde em 1534; e as Novas constitutiones em 1541 promulgadas por Carlo V. Nasceu nesse período um novo gênero literário derivado dos tradicionais regimina sanitatis: os tratados sobre a peste. ${ }^{20}$ Os regimina constituíam-se num gênero literário bem definido que incluía um corpo de conhecimentos comuns: eram

\footnotetext{
${ }^{19} \mathrm{O}$ caso foi narrado pelo historiador milanês Pietro Verri (Storia di Milano, 1825, vol. 4. p. 155) e citado por Manzoni no capitulo 31 de Promessi sposi. A origem da história encontra-se num manuscrito Processo de uma strega famosa, publicado pelo já citado Verri, 1825: 294-95.

${ }^{20}$ Alguns exemplos são: El consiglio per la peste del maestro Piero di Zausignano (1509); e Libellus de preservatione ab epydemia (1360) de Maino de Maineri. Giovanni da Milano foi um médico escritor que elaborou uma síntese das regras da escola salernitana: o primeiro manuscrito remonta ao século XIV. Em 1649, sua Flos medicinae foi impresso como compêndio das regras da Escola salernitana, com o titulo de Schola salernitana sive de conservanda valetudine praecepta métrica. Autore Joanne de Mediolano hactenus ignoti. Ex recensione Zachariae Silvii Médici roterodamnensis. (Roterdami ex Officina Arnoldi Leers, 1649). Um importante texto médico do século XVI conservado na Biblioteca Ambrosiana. Erectio Magistratus Sanitatis (1564) tem edição impressa com notas manuscritas dos médicos Giuseppe e Rocco Casati: Casati, G. e Casati, R. (1564). Erectio Magistratus Sanitatis Bami SCU IV 22.
} 
tratados higiênicos profiláticos com objetivo de divulgação, contendo uma exposição de normas a serem seguidas na vida cotidiana por todos os que quiserem saúde e longevidade. Havia casos em que os regimina eram escritos para preservar a saúde de determinado individuo importante, sendo que o médico esforçava-se para 'personalizar' as regras. Ensinavam ao leitor a melhor conduta diante das "seis coisas não naturais"; sendo que "coisas naturais" eram os elementos constitutivos e funcionais ao organismo: ar; comida e bebida; movimento e repouso; sono e vigília; inanição e repreção; acidentes do animo. Estes eram considerados fatores externos, variáveis, capazes de influenciar o organismo e que, portanto, deviam ser regulados para manter o estado de saúde do organismo. Tendo em vista sintetizar as regras e facilitar a consulta, Ibn Butlan, médico cristã de Bagdad, no século XI escreveu o Tacuina sanitatis, um autentico elenco iconográfico das coisas não naturais ${ }^{21}$. Portanto, a diferenciação entre coisas naturais e coisas não naturais que encontramos no parecer de Clerici, deriva dessa tradição.

Quanto à profissão medica em Milão havia duas figuras: o medico magister (medico físico) e o cirurgião. O mais celebre dos médicos milaneses do século XVI foi Gerolamo Cardano (1501-1576), leitor das escolas médicas de Pavia e Bologna e médico de renome internacional, de grande engenho e de cultura enciclopédica, autor também de uma autobiografia, De própria vita. Outro importante médico milanês do século XVI foi Ludovico Settala (1552-1633). Formado em medicina e filosofia em Pavia em 1572 , associado aos físicos milaneses desde 1573, foi leitor naquela cidade a partir de 1575 , sendo chamado de volta em Milão por Carlo Borromeu para cuidar da peste. ${ }^{22}$ Especialista em síndromes gástricas escreveu o livro De morbis ex mucronata cartilagine evenientibus (Milão, 1632). O estomago foi também a sede dos distúrbios evidenciados no manuscrito de Clerici sobre a erva mate. Apesar do perfil cientifico tão destacado, Settala protagonizou o famoso caso de Caterina de Medici relatado anteriormente.

Ainda em Milão, em 1597, Federico Borromeu criara o projeto de hospício das bruxas que não pude concretizar; ao passo de que as execuções por bruxaria em Milão entre 1560 e 1630 foram nove, todas no período em que Federico Borromeu era cardeal.

Como é possível que figuras tão destacadas do ponto de vista intelectual como o próprio Borromeu e os médicos Settala e Clerici, aderissem à crença no fenômeno da bruxaria e incentivassem práticas persecutórias da mesma?

O medo da bruxaria é um fenômeno que no contexto temporal e geográfico que estamos estudando, deve ser associado ao fenômeno epidêmico da peste. Será preciso aprofundar essa associação para podermos compreender o juízo acerca da erva mate como fenômeno diabólico.

Entre 1629 e 1632, o descuido do Tribunal da Saúde de Milão permitiu o difundir-se da peste ao longo dos festejos de carnaval. Uma vez expandida a epidemia, difundiu-se a crença de que ela fosse causada por 'untores', ou seja, pessoas que deliberadamente espalhavam a doença, através de bálsamos infecciosos colocados nas paredes das casas, sob influencias diabólicas. No mês de maio de 1630, três cônegos do Domo de

\footnotetext{
${ }^{21}$ Alguns regimens se encontram na Biblioteca casanatense em Roma, como por exemplo o Theatrum Sanitatis cod. N. 4182, reproduzido facsimilato em 1940 por Serra e Baglioni, Roma, Libreria dello Stato.

${ }^{22}$ Settala relatou suas experiências nessa circunstância em De peste et pestiferis affectibus, (Milano, 1622) e em dois livrinhos divulgativos: Cura locale dei bubboni pestilenziali, (Milano, 1649); e Preservatione dalla peste, (Milano, 1630). Passado o surto da doença, Settala iniciou a trabalhar no Hospital Maior de Milão, sobretudo cuidando da sífilis. Foi leitor nas escolas de Cannobio a partir de 1554 e escreveu várias pequenas obras de conteúdo vario. Traduziu em latim Hipocrates De aeris, aquis et locis (Colonia 1590). Escreveu: Animadversionum et cautionum medicarum (7 livros ).
} 
Milão (dentre eles Alessandro Magenta homem de confiança de Federico Borromeu e de Girolamo Settala (irmão do médico), relataram terem visto um grupo de pessoas ungirem a parede de uma igreja que separava homens e mulheres. No dia seguinte, vários relataram que as muras da cidade evidenciavam a presença de um balsamo gorduroso. Duas crenças se difundiram em Milão acerca da causa das unções: a do complô diabólico; e a do complô militar e político por parte dos franceses inspirado pelo poderoso Cardeal Richelieu. A difusão da crença do complô diabólico foi tal que Papa Gregório $\mathrm{XV}$ em 1623 escreveu um motu próprio que qualquer suspeito por unções diabólicas fosse entregue ao braço secular da Inquisição para ser queimado vivo. O medo da acusação por impiedade implicou também que a ciência e a medicina se calassem para refuta-la. Houve, porém, alguns que tiveram a coragem de discordar publicamente da crença da bruxaria como causa da epidemia de peste: o padre jesuíta Federico Von Spee (15911635), o qual escreveu Cautio criminalis, seu de processibus contra sagas, 1631 . Von Spee criticava outro colega de Ordem, o padre jesuíta Martinho del Rio (1551-1608) autor das Disquisitiones magicae.

As procissões propiciatórias promovidas pela igreja contribuíram a espalhar o contagio da epidemia; de modo que o contagio somente pude ser contido em 1630, por uma ordem do então Presidente do Tribunal da Saúde Giambattista Visconti, decretando a proibição de grandes concentrações de multidões. De modo que Visconti conseguiu debelar a epidemia em 1631.

Em suma, o medo decorrente da concepção da expansão da doença como efeito de causas não naturais e a gravidade da mesma no meio da população de Milão, está na origem da adesão quase incondicional à teoria da bruxaria. Como assinalado por Manzoni, Federico compartilhava desta visão. E os médicos da cidade em seu saber e prática reforçavam a crença, atribuindo a ela um valor 'científico'. Nesse clima é que Federico desenvolve sua apropriação dos informes sobre a erva mate recebidos das longínquas terras latino-americanas.

\section{O juízo do cardeal: erva mate "tentação insana"}

Borromeu redige as informações sobre a erva mate e suas opiniões a respeito, num manuscrito: De Insanis quibusdam tentationibus liber unus $(1629)^{23}$, onde relata o "estranho caso que acontece nas Índias ocidentais, no Peru, e em outras partes": tanto índios quanto estrangeiros mandam colher uma erva a qual desperta um apetite intensíssimo e doentio, de modo que não conseguem fazer outra coisa a não ser comer dia e noite", de modo que"permanecem neste vicio tão obstinados que falecem neste estado" 24 . E depois cita, sem nomear o autor, o conteúdo do parecer de Clerici: "acreditouse que intervenha algum pacto diabólico oculto e arte e poder, sendo que o fenômeno supera os limites ordinários da natureza" 25 . Desse modo, segundo Federico, a erva mate provocando "desordem" nos indivíduos que a usam, faz com que "padeçam bastante no que diz respeito à saúde e se tornem inaptos a realizar diversas funções”. E finaliza esse juízo fundamentando-o também na avaliação dos médicos: "alguns médicos consultados a respeito na Itália disseram que a ação daquela erva não poderia ser efeito de uma simples virtude natural atribuída ao poder da natureza, mas de espíritos malignos agindo em modo oculto". (Borromeo, 2006, p. 117). Pardal (1937) cita outro documento em que

\footnotetext{
${ }^{23}$ De Insanis quibusdam tentationibus liber unus (1629). Bami. F 30 Inf, n; 2.

${ }^{24}$ Idem. ff. 115-117; trad. nossa

${ }^{25}$ Idem, f. 117.
} 
Borromeu expressa seu juízo acerca da erva: uma carta de 2 de junho de 1619, por ele enviada ao bispo do Paraguai, Don Lorenzo Peréz de Grado, onde recomenda que se empenhe para extinguir o "uso pernicioso da erva". ${ }^{26}$

Portanto, a missiva acima citada de Torre Bollo de 1621 acerca do "parecer da erva" se referiria a este processo. Possivelmente, a carta de Borromeu não logrou os efeitos desejados, pois em 1623, Torres volta a escrever pedindo-lhe envie outra carta ao bispo do Paraguai Julián de Cortázar, exortando-o a intervir com decisão, pondo "remédio de la yerva"27.

Uma possível explicação acerca da demora de as autoridades eclesiásticas do Paraguai tomarem providencias quanto ao "abuso da erva", é que o juízo de Torres Bollo e dos dois jesuítas autores do informe remetido a Borromeu, não era compartilhado de modo unívoco no âmbito da Companhia de Jesus. Além do mais, como vimos anteriormente, o clima cultural e religioso da Milão de Borromeu favorecera uma apropriação peculiar das informações recebidas. Informações que por vez poderiam ser interpretadas e apropriadas de maneira diferente, num diferente universo geográfico e cultural. Veremos a seguir o modo como a erva mate é significada por um importante autor jesuíta Antonio Ruiz de Montoya, ele também, como Torres, missionário em America Latina. ${ }^{28}$

\section{A significação da erva mate no lugar de produção: a visão dos índios transmitida por P. Ruiz de Montoya SI}

Uma das mais antigas fontes acerca do mate é a obra do jesuíta peruano Antônio Ruiz de Montoya, La conquista espiritual: nas primeiras páginas do tratado, ao abordar a descrição do Paraguai, o autor afirma que "a principal moeda que corre como prata, é a erva de que depois diremos" (Montoya, 1639, p. 16. trad. nossa).

O documento de Montoya nos permite uma comparação entre a visão acerca do mate elaborada no contex to das relações entre o cardeal lombardo e seus informantes, e o contexto originário de produção e uso da erva mate em America Latina. No capítulo sétimo da obra, ele aborda a questão da erva mate de modo extenso. Relata que as arvores onde nasce a erva têm grande tronco e folhas grandes. Os índios colhem os galhos e os tostam ao fogo baixo e também colhem as folhas com grande trabalho, sendo que a labuta da colheita da erva mate consome as vidas de milhares de índios. Os índios bebem uma bebida feita com aquela erva que lhes produz inchaço nos pés, nas pernas e no ventre, ao passo de que no rosto ficam apenas pele e osso "figurando a própria morte". Uma vez que juntam cem, duzentos quintais daquela erva, os índios a carregam suportando cargas maiores do que o peso de seu próprio corpo "sem dar-lhes coisa alguma para seu sustento". Muitos morrem esmagados pelo enorme peso da carga, ou despencam ao carrega-las pelos precipícios e penhascos e seus corpos acabam comidos pelos bichos das matas. Montoya relata ainda que Francisco de Alfaro (1548-1601), enviado ao Peru pela Coroa para "remediar" estes males, uma vez observada a situação, estabeleceu junto ao Conselho das Índias justas leis: proibiu os trabalhos forçados dos índios na colheita da erva e proibiu aos índios de realizar a colheita entre dezembro e março,

\footnotetext{
${ }^{26}$ Esta carta não foi localizada na Biblioteca Ambrosiana

${ }^{27}$ Carta de Diego de Torres Bollo a Federico Borromeu 11 de julho de 1623. Bami: G 237, Inf. n. 93, f. $189 \mathrm{f} / \mathrm{v}$.

${ }^{28}$ Acerca do conhecimento das ervas pelos missionários jesuítas na América Latina, veja-se: Deckmann (2014).
}

16 Marina Massimi. Erva mate em debate: Federico Borromeu, jesuítas e médicos ... 3-20. 
estação com clima muito adverso. Infelizmente, estas disposições não foram cumpridas, apesar de terem sido aprovadas pela Coroa de Espanha. Ruiz de Montoya continua o texto denunciando o trabalho escravos dos índios pelos encomenderos espanhóis, por ele mesmo testemunhado na Província de Guairá.

Contrariamente à visão de Borromeu e suas fontes, Montoya narra que o uso da erva não era hábito próprio da tradição dos nativos. O jesuíta levantara informações junto aos velhos nativos de oitenta a cem anos, verificado que na época da infância deles, a erva não era utilizada pelas tribos, nem era conhecida, até que um feiticeiro "que tinha trato com o Demônio" a introduziu dizendo que quem quisesse consultar-se com ele devia beber do chá daquela erva; e assim aconteceu. Desse modo, os índios se acostumaram a usar a erva: "dizem que alivia seus trabalhos e lhes serve de sustento e assim vemos todos os dias que os índios não têm outra coisa por sustento a não ser beber a erva de três em três horas. Esta hespurga o estomago, lhes desperta os sentidos, tira-lhes o sono". Montoya observa que por estes efeitos a erva parece assemelhar-se à que na China chamam de chá; e de fato até o nome é semelhante, pois a erva do Paraguai é chamada pelos índios de "caá". Os espanhóis também tomam esta erva e a têm como remédio contra todos os males e dizem que serve, sobretudo, contra as doenças urinarias. E, "de tanto bebê-la, vimos vários perder o juízo" (Montoya, 1639, p. 29-30).

Ruiz de Montoya elenca outros efeitos nocivos: a perigosa e trabalhosa colheita, o fato de que índios e espanhóis estimam e tomam a erva, erroneamente, como sustento; o alto custo que ela tem nos mercados; o uso supersticioso dela pela feitiçaria. E, quanto a esses abusos, Montoya aproxima o mate de outra erva extraída no Peru: a Coca.

Em suma, as fontes informativas colhidas por Ruiz de Montoya junto aos nativos e suas próprias observações o levam a conclusões que, se forem comparadas com os juízos de Borromeu, apresentam semelhanças e diferenças. A diferença principal é que, segundo Montoya, o uso da erva mate não é um habito próprio da tradição indígena: desse modo, não poderia ser interpretado como indicio de condição selvagem daqueles povos, como fizera Borromeu no texto acima citado. A semelhança entre as elaborações conceituais acerca da erva mate de Ruiz de Montoya e de Borromeu é que, de algum modo, se trata de um habito induzido nos índios por forças demoníacas. Quanto aos efeitos demoníacos da erva mate, porém, as interpretações divergem: Borromeu e seus informantes dentre os quais Torres Bollo, qualificam tais efeitos como demoníacos, sobretudo pela perda das capacidades de entendimento e dos bons hábitos da vontade, resultantes no abandono das vivencias religiosas; já segundo Montoya, os efeitos perversos são principalmente ligados ao trabalho escravo dos índios na colheita do mate, e ao fato que o consumo da erva representa uma ameaça para a sobrevivência dos mesmos. Montoya também enfatiza que o habito de tomar o chá de erva mate é comum dentre os espanhóis, refutação indireta de quanto Federico afirmara acerca de esse uso ser sinal do estado selvagem.

\section{Conclusão}

Para além das apropriações do conceito acima apresentadas, o que acontecera quanto às praticas de uso e comércio da erva mate nos territórios latino-americanos?

Segundo Contini, Castilho e Costa (2012), a erva-mate foi incorporada ao cotidiano de índios e não índios, de forma gradativa e em tempo não tão longo. Desde os primeiros relatos do uso do mate pelos indígenas, feitos pelo Padre Montoya, até sua in- 
corporação aos hábitos espanhóis, decorreram não mais que cem anos. Contudo a expansão do consumo da erva, para além das fronteiras da Coroa Espanhola, aconteceu com maior rapidez. Entre 1610 (ano de chegada dos jesuítas ao Paraguai) e 1628, a erva-mate tornou-se um importante gênero de comércio que se expandiu do Paraguai, para as províncias de Rio da Prata, Tucumã, Chile e Peru (Arróspide, 1997).

Documentos produzidos pelos espanhóis acerca da erva começam a circular em 1597. Segundo Freire (2011), a Instruções de Juan Ortega ao capitão Ruiz Díaz Melgarejo (1567) mencionam a circulação de erva no Guairá. Outro documento de 1603 relata que o comércio da erva funcionava já há quarenta anos. Logo, porém, iniciaram também as proibições: os jesuítas, visando impedir a utilização do trabalho indígena escravo pelos encomenderos, chegaram a ameaçar com excomunhão quem consumisse, produzisse, ou vendesse a erva. No inicio das reduções jesuíticas, em 1610, o governador Diego Marín de Negrón proibiu o comércio da erva. Estas medidas não lograram efeito e o consumo se estendeu ao Alto Peru, ao Chile, ao Equador (Quito), aos mineiros de Potosi. Apesar de, desde 1645, os jesuítas produzirem erva nas missões do Paraná e comercializa-las em Santa Fe, a Congregação Provincial da Companhia de Jesus, reunida em Córdoba em 1665, reafirmou a necessidade de proibir o uso da erva, do tabaco e do chocolate. Todavia, a partir de 1641, instalados em novos territórios na região entre os rios Paraná e Uruguai, eles mesmo começaram também a investir na produção da erva. Ao longo do tempo, a cultura mestiça da região estimulou o hábito de consumir erva, em todas as categorias sociais e grupos étnicos.

Aos poucos, portanto, a produção e o consumo do mate foram se espalhando, tornando-se importante fonte de redito naquelas terras. O conceito da erva mate foi assim sendo modificado pela difusão da prática de comercio e uso do mesmo. O panorama cultural do Ocidente também mudara: em meados do século XVII e inícios do século XVIII, o medo dos fenômenos sobrenaturais afetando a vida dos homens foi dando lugar ao racionalismo iluminista e à concepção de um pensamento cientifico autônomo das crenças religiosas. Desse modo, o tipo de apropriação das informações e de elaboração do conceito de erva mate, ocorridos no período borromaico, já não tinham mais lugar. Tal apropriação e elaboração só tinham plausibilidade no contexto do clima cultural e religioso da Milão dos séculos XVI e XVII; inclusive no contexto dos saberes e crenças médicas da época ${ }^{29}$.

\section{Referências Documentais}

Arquivo e Biblioteca Ambrosiana, Milão (Bami)

\footnotetext{
${ }^{29}$ Já situado no universo mental e cultural do iluminismo cristão do século XIX, Manzoni podia interpretar aquele mundo passado com olhar distanciado, ao mesmo tempo critico e compreensivo. Desse modo, nos Esposos prometidos, Manzoni, após ter tecido a biografia elogiosa do Cardeal Borromeu, termina com a seguinte observação: "Non dobbiamo però dissimulare che tenne con ferma persuasione, e sostenne in pratica, con lunga costanza, opinioni, che al giorno d'oggi parrebbero a ognuno piuttosto strane che mal fondate; dico anche a coloro che avrebbero una gran voglia di trovarle giuste. Chi lo volesse difendere in questo, ci sarebbe quella scusa così corrente e ricevuta, ch'erano errori del suo tempo, piuttosto che suoi: scusa che, per certe cose, e quando risulti dall'esame particolare de' fatti, può aver qualche valore, o anche molto; ma che applicata così nuda e alla cieca, come si fa d'ordinario, non significa proprio nulla. $\mathrm{E}$ perciò, non volendo risolvere con formole semplici questioni complicate, né allungar troppo un episodio, tralasceremo anche d'esporle; bastandoci d'avere accennato così alla sfuggita che, d'un uomo così ammirabile in complesso, noi non pretendiamo che ogni cosa lo fosse ugualmente; perché non paia che abbiam voluto scrivere un'orazion funebre. (Manzoni, Promessi Sposi. Capitulo XXII)".
} 
Borromeu, F. (sd). Per $i$ Viaggi Spirituali o sieno osservazioni fatte nei viaggi e nel leggere viaggiatori. Biblioteca Ambrosiana [Bami]. G $309 \operatorname{Inf}(8)$.

Borromeu, F. (1582-99). Geografia Universale. Bami: G. 24 Inf (6)

Borromeu, F. (sd). Paralela Cosmographica de Sede et Apparitionibus Daemonum Liber Unus. Bami G 5 Inf F 202.

Borromeu, F. (1629). De Insanis quibusdam tentationibus liber unus. Bami. F 30 Inf, n; 2.

Casati, G. e Casati, R. (1564). Erectio Magistratus Sanitatis Bami SCU IV 22.

Clerici. G. A. (sd) De Iudicium de symptomatibus consequentibus ad assumptionem herbae cuiusdam qua Indi tuccumani et paraguainenses utuntur. Bami R106 Sup Fondo Pinelli. ff. 333-334; spagnolo f. 335

Carta de Diego de Torres a Federico Borromeu de 23 de julho de 1606, enviada do Novo Reino Em: Bami [Biblioteca Ambrosiana] G. 251, 237 e 238 (trad.), pp. 475-476.

Carta de Diego Torres a Federico Borromeu, Cordova 19 de março de 1621. Bami: G 254 INF 158 FLS 289-290.

Carta de Diego de Torres Bollo a Federico Borromeu 11 de julho de 1623. Bami: G 237, Inf. n. 93 , f. 189 f/v.

Outro documento dell'erba usata dagli Indiani del Paraguay e Tucuman .Bami. R 106 Sup ff 333r-334r e f. 335, reproduzidos em Belloni, Luigi. Physis, I, 1959, pp. $31-40$.

\section{Referencias Bibliográficas}

Albonico, A.(1990). Il cardinal Federico 'americanista'. Roma: Bulzoni.

Andretta. S. (2007). Giampietro. Dizionario Biografico degli Italiani. Roma: Treccani. Volume 67.

Arróspide, J. L. R. (1997). Antonio Ruiz de Montoya y las reducciones del Paraguay. Assunción, Paraguay: Centro de Estudios Paraguayos "Antonio Guasch".

Belloni L. (1958). La Medicina a Milano fino al Seicento. In: Storia di Milano. Milano: Treccani. Vol. IX, 1958.

- (1959). Demonismo e 'yerba mate' (ilex paraguariensis) nel giudizio del medico G.A. Clerici. Physis rivista di storia della scienza. 1 (1): 31-40.

Borromeu, F. (2006). Paralela Cosmographica de Sede et Apparitionibus Daemonum Liber Unus. Edizione moderna a cura di Francesca di Ciaca, Roma, Bulzoni, 2006.

Chartier, R. (1991). O mundo como representação. Estudos avançados, 1991, n. 11 (5): 173-189.

- (2001). Cultura Escrita, Literatura e História. São Paulo: Editora Art Med. 
Contini, A. Z.; Castilho, M.A.; Costa, R.B. (2012). A erva-mate e os Kaiowá e Guarani: da abordagem etnobotânica à promoção do desenvolvimento local. Interações. 13 (2): 161-168.

Deckmann Fleck, E. C. (2004). Almas em busca da salvação: sensibilidade barroca no discurso jesuítico (século XVII). Revista Brasileira de História, vol. 24, nº 48, pp. 255-300.

(2014). Entre a caridade e a ciência: a prática missionária e cientifica da Companhia de Jesus. (América platina, séculos XVII e XVIII). São Leopoldo: Editoras Oikos e Unisinos.

Del Techo SI, N. (2005) [1673]. História de la Provincia del Paraguay de la Compañia de Jesus. Prologo de Bartolomeu Meliá SI Nueva Edicion, Tomo Único. Asunción: Centro de Estudos Paraguayos Antonio Guasch-Fondec.

Lamalle, E. (1942). Schedario unificato Lamalle sub nomine. Roma: Archivio storico Compagnia di Gesú.

Lozano SJ, P. (1755). Historia de la Compañia de Jesus de la Província del Paraguay. Madrid: Imprenta de Fernández.

Manzoni, A. (1985). Promessi sposi. Milano: Mondadori. Original de 1827.

Mello e Souza, L. (1989). O diabo e a Terra de Santa Cruz. São Paulo: Companhia das Letras.

Pardal R. (1937). Medicina aborigen americana. Buenos Aires: José Anesi.

Pécora, A. (2001). Máquina de Gêneros. São Paulo: Edusp.

Prodi, P. (1971). Federico Borromeo. Dizionario Biografico degli Italiani - Roma: Treccani. Volume 13.

Quevedo dos Santos, J. R. (2012). A regulamentação do trabalho indígena nas Missões Jesuíticas. Revista Latino-Americana de História. Vol. 1, nº 3 - Março de 2012. Edição Especial - Lugares da História do Trabalho, pp. 24-44.

Raj, K (2013). Beyond Postcolonialism and Postpositivism: Circulation and the Global History of Science. Isis, Vol. 104, No. 2 (June 2013), pp. 337-347

Ruiz de Montoya, A. (1639). Conquista espiritual hecha porlos religiosos de la Compañia de Jesus em lãs Provincias del Paraguay, Uruguay, Paranay, Tape. Mardi: Imprensa do Reino.

Safier, N. (2008). Measuring the New World: Enlightenment science and South America. Chicago: Chicago University Press.

(2010) Global Knowledge on the Move: Itineraries, Amerindian Narratives, and Deep Histories of Science. Isis, n. 101, pp. 133-145.

Storni, H. (1975). "El P. Diego Torres Bollo", Cuadernos monasticos, $\mathrm{n}^{\circ}$ 10, Buenos Aires, pp. 451-457.

Vargas Ugarte, R. (1934). El Padre Diego de Torres Bollo. Boletin del Instituto de Investigaciones Historicas. Buenos Aires, Faculdade de Filosofia y Letras 17 (5860), pp. 59-82.

Verri, P. (1825). Storia di Milano. Vol 1-10. Firenze: Le Monnier. 